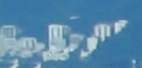

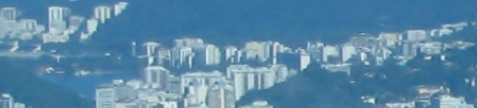

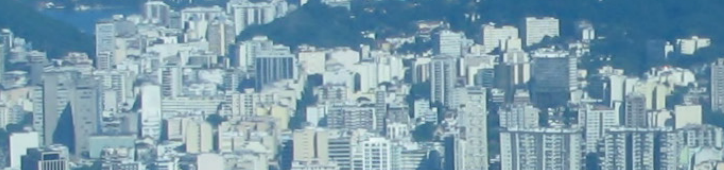

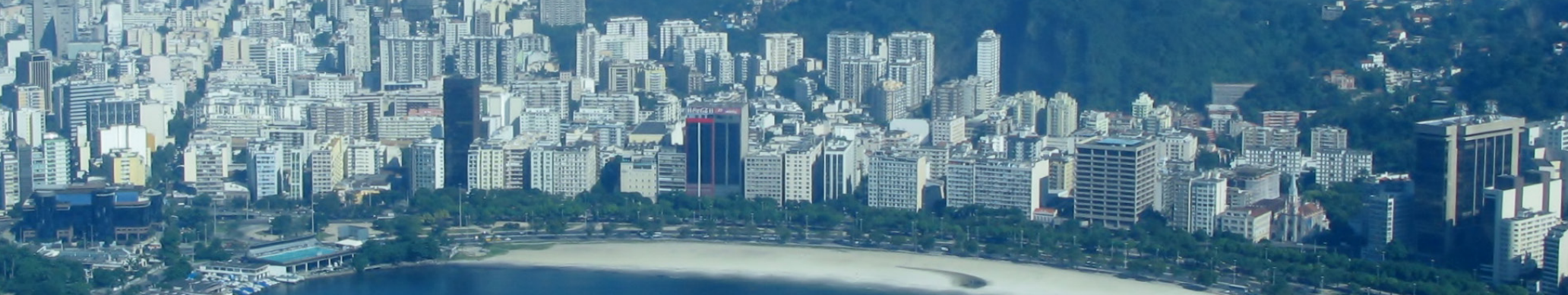
(5) $45 e^{2}$

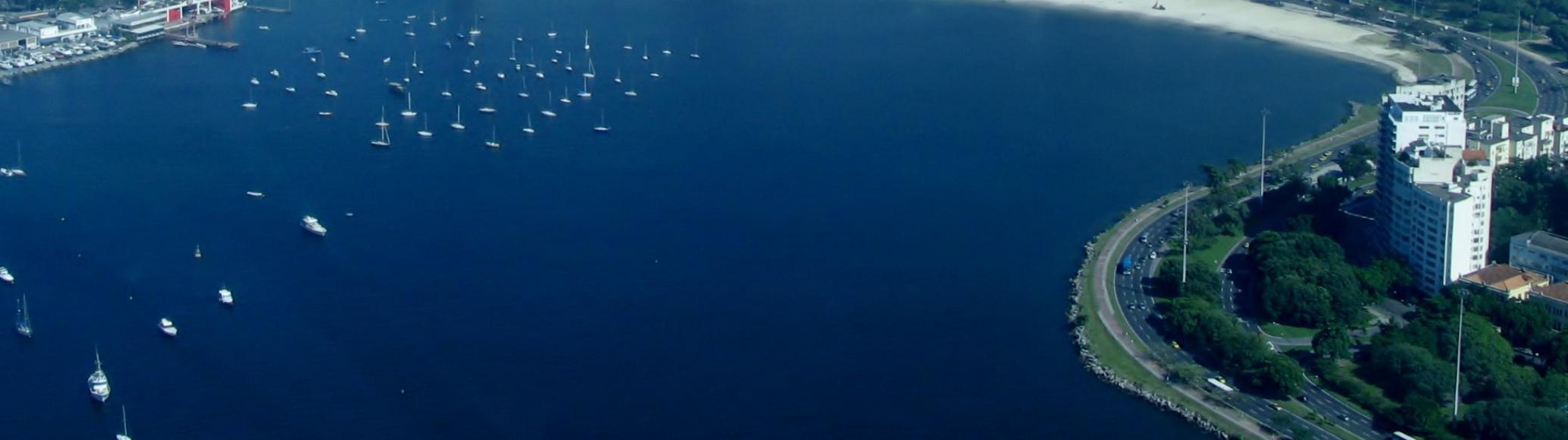




\section{PAISAGEM CULTURAL URBANA E PAISAGEM HISTÓRICA URBANA: O RIO DE JANEIRO E OS DESAFIOS RECENTES PARA A LISTA DO PATRIMÔNIO MUNDIAL}

\section{Rafael Winter Ribeiro}

Doutor em Geografia e Professor Adjunto do Departamento de Geografia na Universidade Federal do Rio de Janeiro

\section{RESUMO}

A adoção da recomendação sobre Paisagens Históricas Urbanas da Unesco em 2011 e a inscrição de partes da cidade do Rio de Janeiro como paisagem cultural em 2012 colocam questões importantes sobre o lugar do urbano no Centro do Patrimônio Mundial. A partir de uma análise sobre a forma como a tipologia de paisagem cultural tem sido usada para inscrição de sítios, no qual predominam aquilo que chamamos de dupla tradição - a tradição paisagista e a tradição geográfica ou vidalina - apontamos para a sua dificuldade de incorporar grandes centros urbanos. $O$ trabalho explora a necessidade de debate sobre a ideia de Paisagem Cultural Urbana e de revisão das tipologias para inscrição de sítios na Lista do Patrimônio Mundial, concorrendo para melhor adequar a abordagem de Paisagem Histórica Urbana que vem sendo fomentada pela Unesco. 


\section{RESUMEN}

La adopción de la Recomendación sobre el Paisaje Urbano Histórico de la Unesco en el año 2011 y la declaración de partes de la ciudad de Río de Janeiro como un paisaje cultural en 2012 plantean cuestiones importantes sobre el papel de las áreas urbanas en el núcleo Patrimonio de la Humanidad. A partir de un análisis de cómo se ha utilizado la tipología paisaje cultural para las declaratorias de sitios, tipificando lo que llamamos la "doble tradición" - la tradición paisajista y la tradición geográfica o vidalina - señalo las raciones de la dificultad de incorporar grandes centros urbanos en la Lista con esta tipología. El artículo explora la necesidad de un debate sobre la idea de Paisaje Cultural Urbano y también la revisión de las tipologías para la inscripción de sitios en la Lista del Patrimonio Mundial, contribuyendo a una mejor implementación del paisaje urbano histórico promovido por la Unesco.

Palabras clave: paisaje cultural urbano, paisaje urbano histórico, Unesco, Río de Janeiro - Brasil.

\section{ABSTRACT}

The adoption of the Unesco's recommendation on Historic Urban Landscapes in 2011 and the nomination of parts of the city of Rio de Janeiro as a cultural landscape in 2012 raise important questions about the role of the urban areas in the World Heritage Centre. After analyzing how the cultural landscape typology has been used to nominate sites, dominate by what we call the double tradition - the landscape tradition and the geographical or vidalin tradition - we show the difficulty of incorporating large urban centers. The paper explores the need for discussion on the idea of Urban Cultural Landscape and the revision of the typologies for nomination of sites on the World Heritage List, contributing to a better implementation of the Historic Urban Landscape approach.

Keywords: urban cultural landscape, historic urbana landscape, Unesco, Rio de Janeiro - Brazil. 


\section{INTRODUÇÃO}

Com o título "Paisagens Cariocas: entre a montanha e o mar", em 2012 foram inscritas partes da cidade do Rio de Janeiro na Lista de Patrimônio Mundial. Mais do que ressaltar a beleza da cidade, os objetivos declarados para a inscrição envolviam diretamente a construção de instrumentos de gestão compartilhada a partir da ideia de paisagem. Apesar do reconhecimento internacional das belezas da cidade e de sua paisagem ser historicamente um dos elementos fundamentais de sua identidade, o processo de candidatura e construção do dossiê de inscrição foi permeado por conflitos e barreiras. A dificuldade de enquadramento do sítio proposto dentro das tipologias existentes na Unesco, associada à incredulidade de se construir um modelo de gestão segundo os moldes aceitos eram apontadas por setores mais conservadores como uma barreira importante.

O que se propunha no caso do Rio de Janeiro não era um modelo tradicional de centro histórico. A parte central e mais antiga da cidade sequer constava da área proposta. $\mathrm{O}$ caminho escolhido foi fazer uma leitura da cidade utilizando-se da ideia de paisagem cultural. A opção pela inscrição dentro da tipologia de paisagem cultural, existente desde 1992 para a inscrição de tipos específicos de sítios que ressaltassem a relação entre natureza e cultura, colocou uma série de questionamento sobre os limites teóricos e práticos dessa tipologia. Nesse sentido, o processo de inscrição da cidade, ao mesmo tempo em que teve que lidar com a construção de valor para o sítio, foi obrigado a dialogar com esses limites e possibilidades da tipologia de paisagem cultural dentro do Centro de Patrimônio Mundial, ao ponto de fazer emergir a ideia de Paisagem Cultural Urbana, subtipologia ainda não reconhecida oficialmente, mas que coloca a questão da paisagem urbana ao mesmo tempo em que outros setores da Unesco desenvolviam uma nova abordagem que preferiram chamar de Paisagem Histórica Urbana.

Neste artigo procuramos fazer uma reconstituição crítica desse processo. Na primeira parte analisamos como a categoria de paisagem cultural tem sido incorporada pelo Centro do Patrimônio Mundial e como a partir desta emerge a ideia de Paisagem Cultural Urbana e sua relação com a abordagem de Paisagem Histórica Urbana. Na segunda parte analisamos as estratégias de atribuição de valor do Rio de Janeiro para a adequação e a obtenção do título. 


\section{PAISAGEM CULTURAL, PAISAGEM CULTURAL URBANA E PAISAGEM HISTÓRICA URBANA: AS RAZÕES DE UM DEBATE}

Quando a Unesco criou a tipologia de Paisagem Cultural em 1992 procurava criar elementos para resolução de um problema que ficava cada vez mais evidente: a dicotomia entre natureza e cultura na Lista de Patrimônio Mundial. A Convenção do Patrimônio Mundial de 1972 ao dividir os bens a serem inscritos em duas categorias, natural e cultural, e ao obrigar os sítios candidatos a se encaixarem em um desses tipos quando da produção dos dossiês e da declaração de valor universal, provocou um visão separada entre natureza e cultura que no final dos anos 1980 já se mostrava anacrônica. No momento em que as discussões sobre desenvolvimento sustentável e meio ambiente alcançaram as reflexões sobre o patrimônio mundial, ficou evidente que aquela divisão rígida entre natureza e cultura colocava vários problemas.

Da reunião entre especialistas de diferentes áreas ocorrida em La Petite Pierre, França, em 1992, saíram as diretrizes para a criação da tipologia de paisagem cultural dentro da Lista de Patrimônio Mundial, que acabou por se tornar referência, dando considerável visibilidade e influenciando toda uma discussão sobre o tema e ações em outras escalas. Não cabe aqui retraçar um histórico da implementação dessa tipologia pela UNESCO, já realizado alhures (RIBEIRO, 2007), mas apontar brevemente suas principais características.

A divisão entre natureza e cultural presente no texto da Convenção de 1972 refletia a ideia de que, para muitos dos conservacionistas da natureza, quanto menos interferência humana houvesse numa área, melhor ela seria qualificada; assim, também para muitos arquitetos, historiadores da arte e outros cientistas das áreas humanas, os movimentos e estruturas, prédios e ruínas eram vistos como fenômenos isolados (FOWLER, 2003). Na verdade, essa concepção refletia a própria origem bipartida da preocupação com o patrimônio mundial, oriunda de dois movimentos separados: um que se preocupava com os sítios culturais, e outro que lutava pela conservação da natureza. Essa dualidade entre natureza e cultura está presente no cerne do Centro do Patrimônio Mundial, tendo sido alvo de várias críticas (MITCHEL \& BUGGEY, 2000), e a tentativa de arrefecê-la é fundadora de uma série de preocupações, como a paisagem cultural. Entender o papel dessa dualidade natureza/ cultura dentro da Unesco nos ajuda a pensar na forma como a categoria de paisagem cultural tem sido utilizada e as dificuldades, por exemplo, para a inscrição de grandes áreas de centros urbanos a partir dessa tipologia. 
Embora o termo 'paisagem cultural' seja oriundo da geografia alemã do final do século XIX e início do século XX, denotando a paisagem que sofreu interferência do homem, em oposição então à paisagem natural, a forma como a categoria tem sido apropriada em políticas de patrimônio é bem mais específica e restritiva. Em função do modelo adotado e dos seus objetivos, para a Unesco, paisagem cultural se transforma em sinônimo de natureza e cultura associadas, e a obrigação de apontar para a relação entre as duas é entendida como central nas atribuições de valor. Nessa concepção, qualquer que seja o tipo de paisagem cultural, ou a tradição incorporada, o foco central, segundo a abordagem da Unesco, deve ser mostrar como natureza e cultura estão associadas. Há pouco ou nenhum espaço para paisagens culturais que não tenham essa conotação.

A partir de uma definição tão ampla e visando maior objetividade para o reconhecimento e atribuição de valor dessas paisagens, elas são divididas em três tipos distintos: 1) a paisagem claramente definida, aquela intencionalmente criada pelo homem, representada nos parques e jardins; 2) a paisagem essencialmente evolutiva, que resulta da ação do homem como uma resposta ao ambiente natural, refletindo o processo evolutivo da sociedade; 3) e a paisagem cultural associativa, aquela cuja inscrição é justificada pelos valores associados a ela, muito mais do que pelas suas transformações físicas e seu agenciamento.

Nessa categorização das paisagens alvo de inscrição da Lista de Patrimônio Mundial, emergem três focos claramente distintos: aquele que valoriza a planificação, os jardins e o paisagismo; um segundo que valoriza a maneira como sociedades, notadamente as tradicionais, agenciaram seu ambiente; e um terceiro, que valoriza os símbolos e valores associados a elementos da paisagem. Essa constituição não é gratuita e está ligada à forma como diferentes ramos do conhecimento se apropriaram da noção de paisagem, conceituando-a e, claro, aos agentes responsáveis por essas definições e ao jogo de forças internas e externas na Unesco.

A forma como a categoria de paisagem cultural tem sido abordada nos dossiês de candidatura tem acompanhado aquilo que venho chamando de dupla tradição da paisagem, ora tem incorporado a tradição paisagista dos arquitetos, ora aquela da geografia tradicional vidalina.

Entre os mais de 80 sítios inscritos hoje como paisagem cultural apesar de sua diversidade, como nas outras tipologias pode-se notar padrões de inscrição. Uma geografia das 
paisagens culturais inscritas pela Unesco atualizada ainda está por ser feita, mas a título de exemplo e apontando conclusões preliminares do trabalho em curso, analisarei aqui sítios inscritos como paisagens culturais em dois países de dois continentes distintos: aquele que, historicamente, tem sido privilegiado para inscrições na Lista e de onde partiu a maior parte das diretrizes para o Centro do Patrimônio Mundial, a Europa, representado aqui neste texto pela Alemanha; e aquele que, historicamente, tem sido marginalizado e, ainda hoje, apesar das ações afirmativas para inscrição de sítios, tem um número bastante reduzido de inscrições, a África, representado aqui pela África do Sul. Trata-se de um exemplo didático e generalista sobre as diferentes apropriações da categoria de paisagem para políticas de patrimônio que, se não contempla o grande universo de paisagens e países com inscrições na Lista, fornece-nos um primeiro olhar para a questão.

De uma maneira geral e esquemática, é possível identificar dois grandes grupos de sítios, associados a duas tradições distintas em relação à paisagem: aquele que chamo aqui de a tradição geográfica, ou vidaliana, e aquele que chamo de tradição paisagista. $\mathrm{O}$ primeiro remete a uma preocupação com a relação homem/natureza pautada, sobretudo, em sociedades tradicionais, nas quais os aspectos considerados "naturais" mantêm predominância na sociedade e na paisagem; o segundo, ao grupo de sítios inscritos como paisagem cultural que remete à tradição do paisagismo, de jardins e áreas planejadas. Analisarei mais detidamente esses dois grupos.

Embora sem citação explícita, a presença daquilo que poderíamos identificar como uma tradição geográfica ou vidalina pode ser percebida na inscrição de uma série de sítios. Tomando como exemplo os dois sítios inscritos como paisagem cultural pela África do Sul, ela fica bem evidente. A "Paisagem Cultural e Botânica de Richterveld" é definida da seguinte forma:

O povo Nama leva ali uma vida pastoral seminômade, testemunho de formas de vida que podem ter persistido por não menos que dois milênios na África Austral. É o único local onde os Nama constroem ainda suas casas cobertas de junco (haru oms). ${ }^{1}$

O sítio foi inscrito sob os critérios (iv) e (v). O primeiro é justificado segundo a ideia de que o modo de vida pastoral dos Nama e suas distintivas casas tradicionais são únicos e demonstram uma longa associação com a paisagem que tem contribuído para o valor

1 Todas as referências às inscrições na Lista do Patrimônio Mundial foram retiradas das descrições dos sítios presentes na website do Centro do Patrimônio Mundial (http://whc.unesco.org). Tradução livre do autor. 
botânico das pastagens. O critério ( $v$ ) é justificado com base na argumentação de que os Nama representam um modo de vida que já foi bastante difundido no sul da África, mas que foi perdido, exceto nesse grupo, nessa localidade.

O segundo sítio inscrito pela África do Sul é denominado "Paisagem Cultural de Mupungbwe" e tem a seguinte descrição:

Trata-se de uma paisagem de savana, espaçada com árvores, arbustos e alguns baobás colossais. Na confluência dos rios Limpopo e Shashe e juntando as rotas norte/sul e leste/oeste no sul da África, Mapungubwe foi o maior reino do subcontinente antes de ter sido abandonado no século XIV. Sobreviveram vestígios quase intactos dos sítios do palácio, com toda a zona de povoamento que dele dependia, e duas capitais anteriores. O conjunto oferece um panorama do desenvolvimento de estruturas sociais e políticas através de cerca de 400 anos.

O sítio foi inscrito sob os critérios (ii), (iii), (iv) e (v). O critério (ii) é justificado pelo sítio conter evidências de um importante intercâmbio de recursos humanos e valores que levaram a profundas mudanças culturais e sociais na África austral entre os anos de 900 e 1.300 DC. O critério (iii) é justificado por Mupungbwe ter sido, até seu desaparecimento no século XIII, o maior povoamento do interior da África. No seu apogeu, o reino se extendeu por área superior a $30.000 \mathrm{~km}$. O critério (iv) foi apresentado por meio do comércio de ouro e marfim em troca de contas de vidro e cerâmica através dos portos do leste africano, com rotas para lugares tão distantes quanto a China. O critério (v) também foi indicado, uma vez que as ruínas ilustrariam o crescimento da sociedade e o impacto de alterações climáticas que levaram ao declínio daquela civilização, como um claro registro de uma cultura que se tornou vulnerável a mudanças irreversíveis no clima.

Se o primeiro sítio analisado pode ser considerado uma paisagem viva, em evolução, o segundo trata-se de uma paisagem arqueológica, ou, para usar os termos empregados pela UNESCO, uma paisagem fóssil. Ambos, entretanto, revelam sociedades tradicionais que se desenvolveram a partir de forte ligação com o ambiente e que podem ainda hoje ser identificadas na paisagem. Meio ambiente, cultura e suas inter-relações são facilmente identificados e valorizados em toda a documentação de inscrição. Nesse discurso, foi a maneira com que essa sociedade se relaciona com um determinado meio que levou à construção de uma cultura que pode ser lida através da paisagem. A paisagem então seria o resultado dessa relação e documento a ser preservado. 
Na geografia francesa do início do século XX, para Paul Vidal de La Blache o conceito de paisagem desempenhava um papel importante, embora esse pesquisador tenha ficado mais conhecido por sua preocupação com o conceito de região. Ao lançar a premissa de que a história de um povo é inseparável da área que ele habita, Vidal de La Blache procurava fazer uma correlação entre o meio e a sociedade que nele se desenvolve, ao mesmo tempo fundando um conhecimento geográfico sem cair em determinações de causa e efeito que, desde o século XVIII, como a Teoria dos Climas de Montesquieu, por exemplo, acompanhava esse tipo de preocupação (Cf GOMES, 1996; BERDOULAY, 1981).

O importante é ressaltar que, para Vidal, a paisagem é moldada pela cultura, fruto da relação entre homem e natureza, gerando um tipo peculiar de viver. O conceito de gênero de vida por ele trabalhado e desenvolvido de maneira mais forte por seus discípulos procura dar conta do produto dessa relação entre cultura e natureza impregnada pela (e impregnando) a paisagem. Os textos de Vidal de La Blache e seus discípulos tiveram importância fundamental na consolidação do conhecimento geográfico e na construção de uma tradição de entendimento da relação homem e natureza que reverbera ainda hoje.

Embora sem citação direta, nota-se fortemente a presença da tradição vidalina, em confluência com a ecologia, na construção da ideia de paisagem cultural na UNESCO. A inserção dessa tradição à Lista de Patrimônio Mundial, embora tenha trazido com ela uma forma de compreender processos naturais e culturais em conjunto, incorpora à paisagem cultural da UNESCO as mesmas críticas direcionadas à Vidal, principalmente sua associação com modos de vida tradicionais e sua dificuldade de inclusão de modos de vida modernos. $A$ necessidade de indicar as bases da relação homem e natureza dificulta a aplicação da ideia de paisagem cultural a sociedades urbanas e complexas, por exemplo, onde a presença e a relação com a natureza não seriam tão evidentes. Essa mesma dificuldade tem feito com que as paisagens culturais inscritas na Lista de Patrimônio Mundial tenham privilegiado paisagens rurais ou de pequenos povoados, onde a "interferência" da natureza pode ser facilmente identificada. Daí a ausência de grandes cidades nessa categoria e a dificuldade para alguns setores mais conservadores de admitirem-nas na Lista como uma paisagem cultural.

O segundo grupo de inscrições está relacionado à tradição da arquitetura da paisagem. O paisagismo tem dado contribuições importantes para conceituações operacionais de paisagem, marcadas sobretudo a partir de um caráter estético e voltado para intervenções. É 
importante lembrar também que, embora no momento de criação da categoria de paisagem cultural esta tenha sido idealizada a partir da tradição geográfica, são os arquitetos que trabalham com patrimônio e/ou os arquitetos paisagistas que, em sua maioria, irão lidar com a categoria de paisagem cultural dentro das instituições de patrimônio e, nesse sentido, a partir da prática a tradição paisagista passa a ter um peso importante.

Tomar como exemplo os sítios hoje inscritos na Lista pela Alemanha como paisagem cultural é revelador dessa tradição. Hoje são três os sítios inscritos como paisagem cultural na Alemanha: os Jardins de Dessau-Wörtlitz, o Parque de Muskau / Mużakowski e a paisagem cultural do Vale do Reno². Os Jardins de Dessau-Wörtlitz são assim definidos:

O reino dos jardins de Dessau-Wörlitz é um exemplo excepcional de concepção paisagista e de urbanismo do século XVIII, o Século das Luzes. Seus diversos componentes edifícios remarcáveis, parques, jardins ingleses e terras agrícolas sutilmente modificadas - preenchem de maneira exemplar funções estéticas, educativas e econômicas.

Esse sítio foi inscrito sob os critérios (ii) e (iv). O primeiro por ser considerado um exemplo excepcional da aplicação de princípios filosóficos do lluminismo para o desenho da paisagem, que integraria arte, educação e economia, num todo harmonioso; o segundo pelo fato de o século XVIII ser considerado um período seminal para o desenho da paisagem no qual o sítio é uma ampla ilustração.

O segundo é um sítio binacional, na fronteira entre a Alemanha e a Polônia, o Parque de Muskau / Mużakowski:

O parque de 559,90 ha, situado de um lado e outro do rio Neisse na fronteira entre a Alemanha e a Polônia, foi criado pelo príncipe Hermann von PücklerMuskau entre 1815 e 1844. Inscrevendo-se harmoniosamente na paisagem agrícola de seu entorno, esse parque inaugura novas concepções paisagistas e influenciou o desenvolvimento da arquitetura paisagista na Europa e na América.

Foi inscrito sob os critérios (i) e (iv). O critério (i) foi incluído uma vez que, se avaliado como uma peça de desenho da paisagem, o sítio é um dos melhores exemplos de um extenso

2 Um quarto sítio, a Paisagem Cultural de Dresdem, no Vale do Elba, foi retirado da Lista em 2009 em função de intervenções, notadamente a construção de uma ponte, consideradas como incompatíveis com os valores inscritos na Declaração de Valor Universal Excepcional do sítio. Para uma discussão mais detalhada sobre o processo que levou à exclusão desse sítio da Lista de Patrimônio Mundial, ver: Albert; Gaillard (2012) 
parque europeu. Se avaliado com as normas e preceitos de sua época, destaca-se como sendo uma peça excepcional de "melhoria" da paisagem que criou novos caminhos em termos de paisagem feita pelo homem. O critério (iv) foi incorporado uma vez que o sítio é identificado como precursor de novas abordagens no desenho de paisagens na cidade e no campo, influenciando o desenvolvimento da arquitetura da paisagem como uma disciplina.

O terceiro sítio inscrito como paisagem cultural é o Vale do Reno:

Os $65 \mathrm{~km}$ do médio vale do Reno, com seus castelos, suas cidades históricas e seus vinhedos, ilustra de maneira viva a perenidade da implicação humana na paisagem natural espetacular e diversificada. Esta paisagem está intrinsecamente ligada à história e lendas e exerce, através dos séculos, uma influência poderosa sobre escritores, pintores e compositores.

O sítio foi inscrito sob os critérios (ii), (iv) e (v). O critério (ii) foi escolhido porque o Vale do Reno foi uma das rotas de transporte mais importantes da Europa que, por dois milênios, facilitou a troca de culturas entre o Mediterrâneo e no norte do continente. O critério (iv) foi incluído pelo sítio ser identificado como uma paisagem cultural orgânica excepcional e seu caráter atual ser definido tanto por sua configuração geológica e geomorfológica quanto pelas intervenções humanas. Já para o critério (v), o médio Vale do Reno é identificado como uma forma excepcional de evolução da vida e dos meios de comunicação em um vale estreito. Os terraços executados em suas encostas íngremes, em particular, moldaram a paisagem de muitas maneiras por mais de dois milênios. Entretanto, essa forma de uso da terra estaria sob diferentes pressões e em risco de desaparecimento e por isso seria necessária a sua inscrição.

Nota-se, sobretudo nos dois primeiros, uma predominância de paisagens projetadas, jardins e construções que remetem ao agenciamento planificado da paisagem e à valorização dos projetos que foram realizados. A natureza aqui é totalmente dominada e controlada pelo homem, seguindo preceitos estéticos e sociais. Se parques e jardins já haviam sido alvo de inscrições na Lista de Patrimônio Mundial e entendidos como monumentos, a captura da categoria de paisagem cultural para sua inscrição valoriza o aspecto de intervenção e domínio sobre a natureza.

Essa dupla tradição encontra-se presente na forma como os sítios têm sido selecionados e tem, em parte, influenciado também a formação de políticas nacionais de proteção da 
paisagem, como no caso brasileiro (RIBEIRO, 2011), não sem alguns problemas e conflitos (RIBEIRO, 2010). A maneira como essas duas tradições predominam nas inscrições dificulta tanto a consolidação de outros olhares e outras tradições como a incorporação de sítios que não se encaixam dentro de uma ou outra lógica. A forma original com a qual o termo paisagem cultural foi criado há mais de um século na Alemanha, denotando simplesmente a paisagem alterada pela cultura do homem, permanece em grande parte ignorada. As restrições para inscrição de espaços urbanos dentro dessa categoria são indicadores dessa dificuldade; afinal, qual melhor exemplo de uma paisagem alterada pelo trabalho do homem do que uma paisagem urbana?

Ao mesmo tempo em que essas dificuldades com relação à tipologia de paisagem cultural ficavam evidentes, setores associados à preservação de centros históricos passaram a identificar de forma cada vez mais forte a necessidade de abordagens mais amplas, que integrem ao mesmo tempo o centro histórico à área urbana na qual ele está inserido e as práticas culturais e valores imateriais associados ao sítio. Foi com esse espírito que foi editado em 2005 o Memorando do Viena, adotado na "Conferência Internacional sobre Patrimônio Mundial e Arquitetura Contemporânea - Gerindo a Paisagem Histórica Urbana” (UNESCO, 2005). Voltado para uma preocupação com intervenções arquitetônicas recentes que afetam os centros históricos reconhecidos como patrimônio, o documento procura ressaltar a relação intrínseca de sítios preservados com as áreas nas quais estão implantados. O documento construído é nomeadamente voltado para cidades históricas já inscritas ou em processo de inscrição na Lista de Patrimônio Mundial, assim como grandes cidades que tenham monumentos e sítios inscritos dentro de seu território. Ele define a paisagem histórica urbana como um conjunto de qualquer tipo de edifícios, estruturas e espaços abertos, nos seus contextos natural e ecológico, incluindo sítios arqueológicos e paleontológicos, constituindo assentamentos humanos em um ambiente urbano sobre um período relevante de tempo, com sua coesão e valor sendo reconhecidos pelos pontos de vista arqueológico, arquitetural, pré-histórico, histórico, científico, estético, sociocultural ou ecológico. Na mesma definição reconhece também que a paisagem tem moldado a sociedade moderna e tem grande valor para nosso entendimento de como nós vivemos hoje.

Embora o documento afirme que a ideia de paisagem histórica urbana vá além de termos tradicionais como centros históricos, conjuntos e entorno, comumente usados nas leis de 
proteção e cartas, para incluir um contexto territorial e de paisagem mais amplo, a escolha infeliz do título pode revelar, na verdade, mais do que uma ampliação da ideia de patrimônio, mas novas formas de tratar velhos objetos. A velha ideia de cidade histórica ainda está presente de forma bastante forte e o que se parece buscar, muitas vezes, é a construção de um novo aparato para tratá-la. O entendimento de contextos que não se encaixam dentro da ideia ainda é bastante restrito.

Ela surge da preocupação de que várias cidades históricas hoje são muito bem preservadas com relação a suas construções e espaço urbano, mas teriam perdido muito de seus usos e valores tradicionais a partir de processos como gentrificação, expulsão de população e apropriação pelo turismo. Cidades como Veneza na Itália são constantemente apontadas como exemplos desse antigo modelo de proteção considerado ultrapassado, que preservou suas construções, mas as esvaziou de seus usos e sentidos originais. Assim, um novo paradigma de conservação dessas áreas deveria se preocupar com o todo, com a população, seus usos e o 'espírito do lugar' - essa tem sido a inquietação que envolve as discussões sobre a ideia de paisagem histórica urbana. Entretanto, sua amplitude se restringe a espaços urbanos considerados "históricos". Nas palavras do ex-diretor do Centro do Patrimônio Mundial e um dos seus defensores:

Historic Urban Landscapes does not constitute a separate heritage category. On the contrary, the concept remains within the established parameters of historic urban areas, while trying to add a new lens to the practice of urban conservation: a broader territorial view of heritage, accompanied by a greater consideration of the social and economics functions of an historic city. (BANDARIN, 2012, p. 223)3 .

Com dois mentores e articuladores principais da ideia, Francesco Bandarin e Ron Von Oers, uma série de encontros de especialistas e publicações foi realizada até a adoção da Recomendação sobre Paisagem Histórica Urbana - HUL, na sigla em inglês - em novembro de 2011. Ela parte de uma definição muito próxima daquela do memorado de Viena: paisagem histórica urbana é a área urbana entendida como resultado de camadas de valores e atributos naturais e culturais, se estendendo além da noção de centro histórico

3 Em tradução livre do autor: "Paisagens históricas urbanas não constituem uma categoria em separado de patrimônio. Ao contrário, seu conceito continua dentro dos parâmetros estabelecidos para áreas urbanas históricas, ao mesmo tempo em que tenta adicionar novos olhares para a prática da conservação urbana: uma visão territorial mais ampla do patrimônio, acompanhada de uma maior consideração das funções sociais e econômicas de uma cidade histórica." 
ou conjunto, em um amplo contexto urbano e seu assentamento geográfico. Das reuniões após a publicação do memorando de Viena até a edição da Recomendação em 2011, o que resultou foi um documento que indica uma abordagem e não uma nova tipologia, trata-se agora de uma forma de atuar sobre as cidades históricas e de uma recomendação que pretende não se limitar apenas aos sítios inscritos pelo Centro de Patrimônio Mundial, mas todos aqueles que se enquadrem nessa ideia.

Um dos aspectos notáveis nessa discussão é como não aparece menção à tipologia de paisagem cultural, quase como se esta não fosse mesmo adotável para cidades e então cria-se uma abordagem nova para tratar as cidades, usando muito das ideias que estão presentes na discussão sobre paisagem cultural. Uma tipologia, a paisagem cultural, e uma abordagem, a paisagem histórica urbana, que parecem não dialogar entre si nos documentos, a despeito de suas potencialidades e pontos em comum. O resultado disso é uma tipologia para determinados objetos - áreas rurais, pequenas cidades, populações tradicionais e parques - e uma abordagem para as cidades, assumindo uma diferenciação entre ambos.

São poucos os especialistas envolvidos nessa discussão a partir das instituições de patrimônio como Unesco e Icomos que assumem a relação entre as duas ideias, a de Paisagem Histórica Urbana e a de Paisagem Cultural Urbana. Patricia O’Donnell (2008), uma das poucas a tocar no assunto, reconhece que ambos correspondem a termos intercambiáveis e que podem valorizar uma abordagem além do visual, procurando fazer uma associação com uma terceira ideia que se desenvolveu nos últimos anos que é a de espírito do lugar.

Entretanto, do ponto de vista das ações dentro do Centro do Patrimônio Mundial, foi a discussão em torno da candidatura do Rio de Janeiro que colocou de maneira mais forte a questão. A proposta, ao não se enquadrar dentro do modelo de cidade histórica e ao procurar um enquadramento a partir da tipologia de paisagem cultural colocou de maneira mais forte a questão da paisagem cultural urbana. Como veremos adiante. 


\section{O DESAFIO IMPOSTO PELO RIO DE JANEIRO: A PAISAGEM CULTURAL URBANA}

A inscrição do Rio de Janeiro, em 2012, sob o título Paisagens Cariocas, entre a montanha e o mar, incorpora dentro da tipologia de paisagem cultural da Unesco algo que até então inexistia: uma grande cidade. Centros históricos, em pequenas, médias ou grandes cidades têm sido os bens mais representados dentro da Lista, totalizando, até 2011, mais de 300 sítios, num total de 936 inscrições entre sítios naturais, culturais e mistos (BANDARIN, 2012). Entretanto, a categoria de paisagem cultural jamais tinha sido usada para inscrição de um sítio em uma grande cidade. Como visto anteriormente, se a ideia original de paisagem cultural, quando a palavra começou a ser empregada no final do século XIX por geógrafos alemães, significava paisagem transformada pela cultura, então nada mais original para representar uma paisagem transformada pela cultura do que a paisagem urbana. Entretanto, como apontei até aqui, a forma como a tipologia havia sido apropriada pela Unesco e a hegemonia da dupla tradição dificultavam sua aplicação para uma grande metrópole, segundo os moldes adotados até então.

A tentativa de ampliação para áreas urbanas de uma abordagem mais integradora, a partir de setores ligados à Unesco, também como vimos, vinha sendo defendida pela criação de uma nova abordagem - a de paisagem histórica urbana (BANDARIN, 2012; BANDARIN \& OERS, 2012). Entretanto, ela representa muito mais um novo olhar para um velho objeto patrimonial - o centro histórico - do que a possibilidade de incorporação de novos sítios ou novos objetos.

Dessa maneira, a ideia de paisagem histórica urbana não dá conta de áreas urbanas que não se enquadrem dentro de uma concepção de cidade histórica, mesmo numa concepção mais ampla. O valor "histórico-cultural" ainda é aquele que preside a sua proteção. O que fazer então com áreas urbanas que constituem importantes significados para determinados grupos, mas que não se encaixam nem num sentido ampliado de "centro histórico"? A tipologia de paisagem cultural aplicada para cidades, se não restrita aos modelos de tradições incorporados até agora pode suprir parte dessa deficiência através da ideia, ou uma subtipologia, de Paisagem Cultural Urbana.

O caminho encontrado para a inscrição do Rio de Janeiro dialoga com todas essas tradições e abre uma brecha para um entendimento mais amplo de patrimônio mundial, permitindo então que se fale de paisagem cultural urbana. Ao incorporar diferentes tradições e avançar 
na ideia do que representa uma paisagem cultural, o urbano passa a ser objeto de interesse, independente de seu caráter "histórico" no sentido tradicional como vinha sendo empregado.

No caso do Rio de Janeiro, como indicado na Figura 1, a área que foi inscrita valoriza o discurso das intervenções humanas sobre um sítio já excepcional, que lhe atribuiu maior qualidade, sendo constitutivo da identidade da cidade e reconhecido mundialmente. Não cabe aqui recuperar todo o longo processo de preparação da inscrição, mas indicar que os setores selecionados são divididos em quatro áreas, três correspondendo às áreas do Parque Nacional da Tijuca e ao Jardim Botânico e um quarto setor, que corresponde àquilo que foi denominado de "bordas desenhadas pelo trabalho humano", englobando a entrada da baía de Guanabara e seus fortes históricos de ambas as margens, o Monumento Natural Pão de Açúcar, o Parque do Flamengo e a enseada de Botafogo, além da praia de Copacabana e seu calçadão, desenhado por Roberto Burle Marx. Se num primeiro olhar a tradição do paisagismo está bem representada e a forma como o sítio foi apropriado pela sociedade também, é na área que permaneceu inscrita como zona de amortecimento que está talvez a grande inovação e o maior desafio.

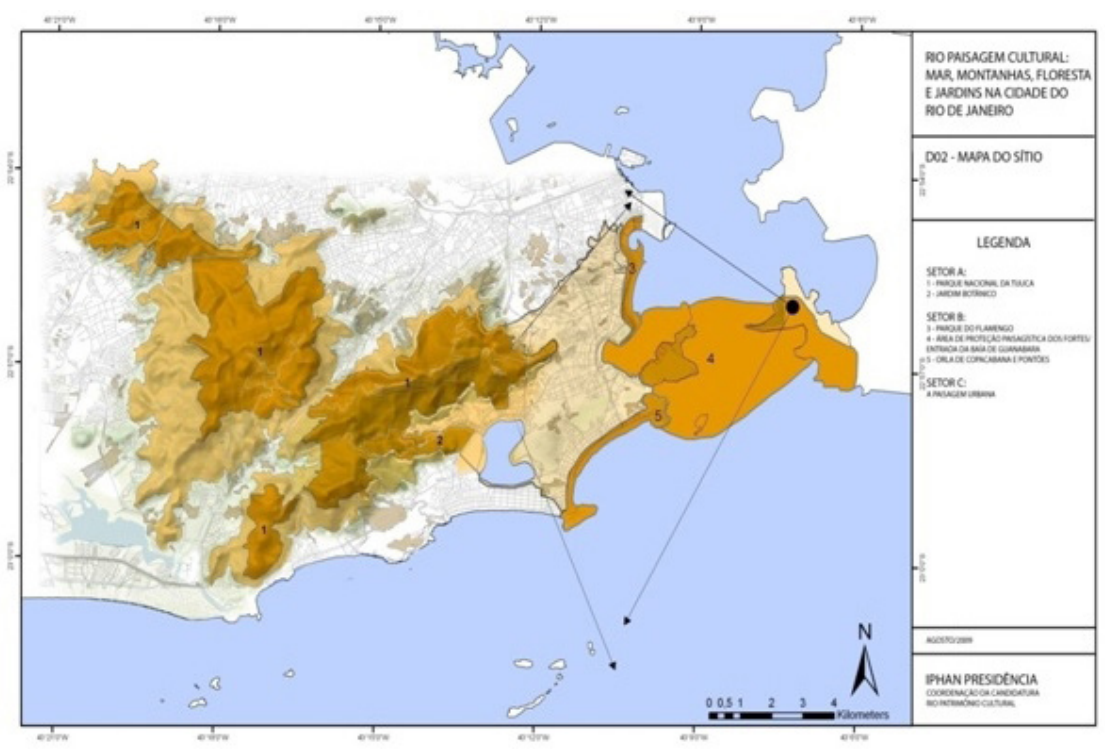


Trata-se de uma área que em 2010 possuía mais de 490 mil habitantes, com bairros importantes da cidade como Botafogo, Copacabana, Laranjeiras e Flamengo, em permanente transformação, numa cidade que se prepara para receber eventos que demandam grandes intervenções urbanísticas, como a Copa do Mundo e os Jogos Olímpicos. A partir do valor universal excepcional adotado - a forma como essa cidade se desenvolveu se relacionando com a montanha e o mar -, uma nova ideia de paisagem cultural está sendo adotada e se diferencia daquela dupla tradição, sem deixar de lado o foco central da cultura im pregnada na paisagem.

Ao mesmo tempo, a ausência do centro histórico no sítio inscrito ou na zona de amortecimento também é paradigmática de uma nova forma de atribuição de valor que não se faz refém exclusiva do valor histórico, mas que tem na espacialidade do bem seu principal elemento balizador. No caso da atribuição de valor para a inscrição do sítio, são as relações sócio-espaciais que estão no centro da atenção. A paisagem é fruto dessa relação. São essas relações sócio-espaciais que constituem o valor universal e excepcional. Nesse sentido, os instrumentos de proteção e de gestão tem que ser também pensados a partir disso e se libertarem do fetiche da forma que integrou as ações do Patrimônio Mundial durante tantas décadas. A forma espacial é sem dúvida importante e está em conexão direta com as relações sócio-espaciais que configuram uma dada paisagem, mas ela tem que ser pensada de maneira diferente daquela como tem sido tratada. A mudança de formas tem que ser vista de maneira diferente ao se pensar em uma paisagem cultural urbana.

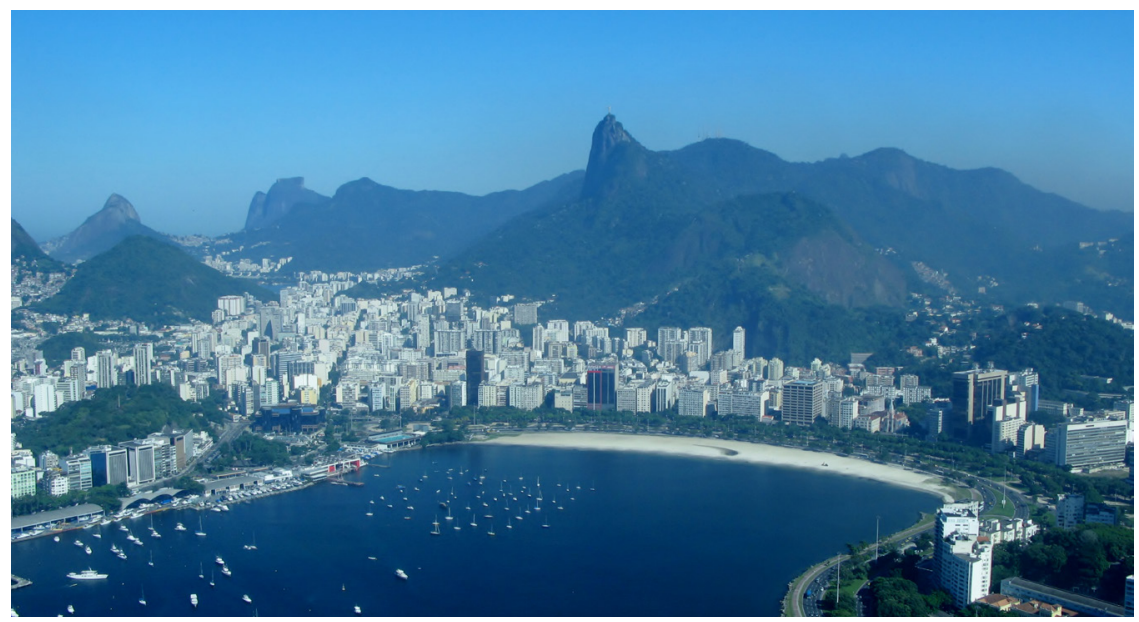

Rio Patrimônio Mundial, Enseada de Botafogo e Corcovado. Fonte: IPHAN, 2009 
A inexistência de uma tipologia reconhecida capaz de permitir um reconhecimento dos valores urbanos e das suas relações espaciais, mais do que simplesmente as formas, colocou problemas sérios à candidatura do Rio de Janeiro. Fez também com que a delimitação do sítio proposto excluísse áreas da cidade que também representam parte importante dessas relações, mas que estão em constante transformação. A inclusão dessas áreas dentro da zona de amortecimento, esperando uma discussão e ampliação da noção de paisagem cultural urbana foi uma das estratégias cogitadas quando da elaboração do dossiê. Na figura 2 observa-se a praia de Botafogo e o Parque Nacional da Tijuca, com a montanha do Corcovado, incluídas dentro do sítio, e a parte urbanizada entre ambos que teve que ser colocada dentro da zona de amortecimento, por inexistência de uma tipologia adequada ou, antes, por leituras conservadoras do que representa a paisagem cultural e como geri-la. Diferente das áreas correspondentes às paisagens projetadas à beira mar, que encontraram uma facilidade maior de inscrição, uma vez que se encaixam dentro de modelos consagrados de atribuição de valor e de uma apreciação estética e de gestão, como o Parque do Flamengo, na figura 3.

Tal fato aponta para a necessidade urgente de se discutir as tipologias existentes para inscrição de sítios na Lista de Patrimônio Mundial e como a ideia de Paisagem Cultural Urbana poderia contribuir para uma transformação significativa na forma como os processos de atribuição de valor são executados e como a gestão é planejada.

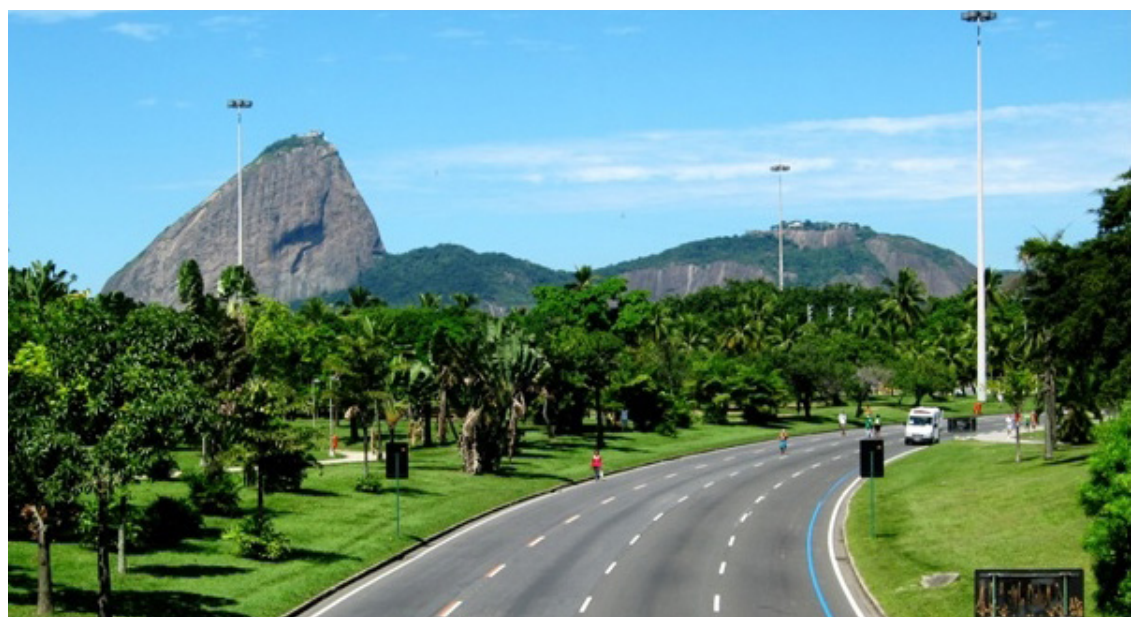


Não basta criar uma ferramenta poderosa como se pretende a de paisagem histórica urbana para o entendimento do patrimônio se as tipologias para inscrição não forem atualizadas e continuarem a dificultar a inscrição desses valores na Lista.

A inscrição do Rio de Janeiro é muito recente e a sua repercussão ainda precisa de mais tempo para ser analisada. O sucesso ou não da construção do modelo inovador e a aplicação do plano de gestão, entregue apenas em 2014, dois anos após a inscrição, em função do reconhecimento por parte dos órgãos avaliadores e do Centro do Patrimônio Mundial do ineditismo da inscrição e das dificuldades para a montagem de um modelo de gestão sem igual até aquele momento, dirá muito se estamos diante de uma potencial transformação e incorporação de novos valores à Lista de Patrimônio Mundial.

Além das vantagens para a preservação e o desenvolvimento sustentável que são esperadas com a inscrição na Lista de Patrimônio Mundial, o Rio de Janeiro transforma-se num laboratório, avançando para um novo olhar sobre o patrimônio e para novas políticas públicas que incorporem os desafios do século XXI para a preservação do patrimônio, capazes de ir além de velhos olhares e tradições sem, no entanto, se desfazer deles.

\section{CONSIDERAÇÕES FINAIS}

Apesar de não existir uma tipologia ou uma recomendação sobre paisagem cultural urbana, ao ter a sua inscrição aceita na Lista do Patrimônio Mundial em 2012, o Rio de Janeiro foi autoproclamado pelas autoridades brasileiras a primeira Paisagem Cultural Urbana inscrita, como parte das estratégias para a ampliação das discussões em torno do tema. Porém, nos últimos anos, parece ter havido um interesse muito maior na discussão sobre a abordagem de Paisagem Histórica Urbana em detrimentos da de Paisagem Cultural Urbana. Parte disso pode ser atribuído à geopolítica interna da Unesco e à incontestável supremacia dos centros históricos dentro da Lista de Patrimônio Mundial, o que faz com que os problemas relacionados a essa tipologia tenham uma visibilidade muito maior, além de mobilizar setores importantes dentro das instituições de patrimônio. Entretanto, o que a ideia de paisagem cultural urbana tem a mostrar é que a cidade como patrimônio pode ser algo muito mais diverso do que a abordagem histórica, ou a abordagem a partir dos centros históricos, mesmo numa visão ampliada. 


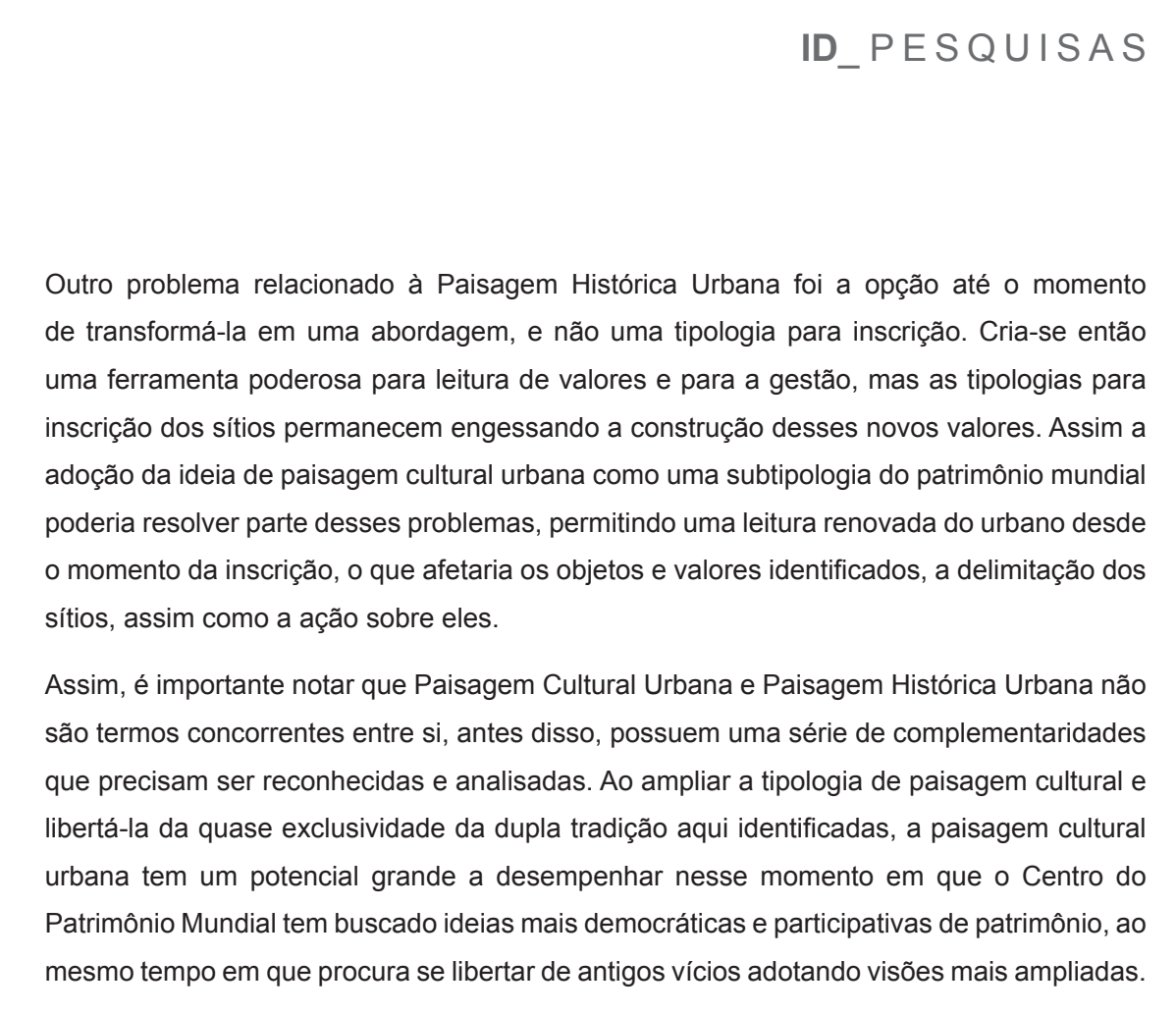




\section{REFERÊNCIAS BIBLIOGRÁFICAS}

ALBERT, M. T.; GAILLARD, B. (2012). "The Dresden Elbe Valley. An example for conflicts between political power and common interests in a World Heritage Site”. London: Routledge, p. 325-344. In: TAYLOR, Ken; LENNON, Jane L. (orgs.). Mananging Cultural Landscapes.

ANDERSON, B. (2008). "Comunidades Imaginadas. Reflexões sobre a origem e a difusão do nacionalismo". São Paulo: Cia das Letras.

BANDARIN, F.; OERS, R. (2012). "The Historic Urban Landscape. Managing Heritage in an Urban Century". Oxford: Blackwell.

BANDARIN, F. (2012). "From paradox to paradigm? Historic Urban Landscape as an urban conservation approach". London: Routledge, p. 213-231. In: TAYLOR, Ken; LENNON, Jane L. (orgs.). Mananging Cultural Landscapes.

BERDOULAY, V. (1981). "La formation de l'école française de géographie (1870-1914)". Paris: Bibliothèque Nationale.

FOWLER, P. (2003). “World Heritage Cultural Landscapes 1992-2002”. Paris: Unesco.

GOMES, P. Cesar da Costa (1996). “Geografia e Modernidade”. Rio de Janeiro: Bertrand Brasil.

IPHAN- Instituto do Patrimônio Histórico e Artístico Nacional (2009). Rio de Janeiro: Carioca Landscapes, Between the Mountain and the Sea. Nomination Document. Rio de Janeiro/Brasília: IPHAN.

JOKILEHTO, J. (2006). "Defining the outstanding universal value”. World Heritage. City \& Time 2 (2): 1.

MITCHEL, N.; BUGGEY, S. (2000). "Protect Landscapes and Cultural Landscapes: taking advantage of diverse approaches". The George Wright Forum, v. 17, n.1.

O'Donnell, P. M. (2008). “Urban Cultural Landscapes \& the Spirit of Place”. Canada: 16th ICOMOS General Assembly and International Symposium: 'Finding the spirit of place-between the tangible and the intangible', 29 sept - 4 oct 2008, Quebec.

RIBEIRO, R. W. (2007). Paisagem Cultural e Patrimônio. Rio de Janeiro: IPHAN.

RIBEIRO, R. W. (2010). "Os ídolos da paisagem: caminhos e descaminhos da relação entre paisagem e patrimônio". Rio Claro: $1^{\circ}$ Congresso de Organização Espacial, Unesp. 
RIBEIRO, R. W. (2011). "Possibilidades e limites da categoria de paisagem cultural para a formação de politicas de patrimônio". Belo Horizonte: Forum, p. 255-268. In: CUREAU, S.; SOARES, I. V.; LAGE, C. M. F. (orgs). Olhar multidisciplinar sobre a efetividade da proteção do patrimônio cultural.

UNESCO (2005). Vienna Memorandum on World Heritage and Contemporary Architecture - Managing the Historic Urban Landscape. Paris: WHC-05/15.GA/INF.7.

UNESCO (2011). Recommendation on the Historic Urban Landscape. Paris: Unesco, http://whc.unesco. org/en/activities/638

UNESCO. COMITE INTERGOUVERNEMENTAL POUR LA PROTECTION DU PATRIMOINE MONDIAL, CULTUREL ET NATUREL (2011). Orientations devant guider la mise en œuvre de la Convention du patrimoine mondial. Paris: Centre Du Patrimoine Mondial. 